\title{
Erratum to: The individualisation of a dog bite mark: a case study highlighting the bite mark analysis, with emphasis on differences between dog and human bite marks
}

\author{
Herman Bernitz • Zephné Bernitz • \\ Gerhard Steenkamp • Ryan Blumenthal • Gerrit Stols
}

Published online: 30 October 2014

(C) Springer-Verlag Berlin Heidelberg 2014

\section{Erratum to: Int J Legal Med (2012) 126:441-446 DOI: 10.1007/s00414-011-0575-4}

The original article contained errors. Below are the necessary updates and changes.

\section{A. Reference List Updates/Changes}

2. Jones JS (2001) Almost Like a Whale. Transworld Publishers, London.

The online version of the original article can be found at http://dx.doi.org/ 10.1007/s00414-011-0575-4.

\footnotetext{
H. Bernitz $(\bowtie)$

Department of Oral Pathology and Oral Biology,

School of Dentistry, University of Pretoria,

P.O. Box 1266, Pretoria 0001, Gauteng, South Africa

e-mail: bernitz@iafrica.com

Z. Bernitz

Veterinary Consultant,

P.O. Box 1276, Middelburg, Mpumalanga, South Africa

\section{G. Steenkamp}

Department of Companion Animal Clinical Studies,

Faculty of Veterinary Science,

University of Pretoria,

Onderstepoort, Pretoria, South Africa

R. Blumenthal

Department of Forensic Medicine, Faculty of Health Sciences,

University of Pretoria,

Pretoria, South Africa

G. Stols

Department of Science, Mathematics and Technology Education, University of Pretoria,

Pretoria, South Africa
}

3. Sacks JJ, Sinclair L, Gilchrist J (2000) Breeds of dogs involved in fatal human attacks in the United States between 1979 and 1998. J Am Vet Med Assoc 217:836-840

4. De Munnynck K, van de Voorde W (2002) Forensic approach of fatal dog attacks: a case report and literature review. Int J Leg Med 116:295-300

5. Shields LB, Bernstein ML, Hunsaker JC 3rd, Stewart DM (2009) Dog bite-related fatalities: a 15-year review of Kentucky medical examiner cases. Am J Forensic Med Pathol 30:223-230

6. Lauridson JR, Myers L (1993) Evaluation of fatal dog bites: the view of the medical examiner and animal behaviorist. J Forensic Sci 38:726-731

\section{B. Text Updates/Changes}

Page 441, Introduction, line 5 from bottom "beast that preserves much of its primordial self [2]."

Page 442, left column:

- Lines 3-4 "only recently has public awareness of this health problem increased [4]".

- Lines 4-6 "Seventy percent of fatal dog bite attacks are committed by a pet dog within the owner's yard or its proximity [5]."

- Lines 9-10 "other breeds may bite and cause fatalities at higher rates [3]."

- Line 12-13 "breed specific ordinances raises constitutional and practical issues [3]."

- Line 15-16 "public policy concerning dangerous dogs $[3,5] . "$

- Line 16-18 "The involvement of more than one dog may account for the severity of injuries due to pack behaviour [6]." 
- Line 24-25 "diabetes mellitus, deafness and blindness) has been described by several other authors $[4,6,9] . "$

- Line 30-31 "injuries to the head and neck regions is typically reported in the literature $[4,5,10$, 11]."
- Line 44-45 "procedures to be followed when examining bite marks [5, 12-16], "

Page 442, right column, under General principles in forensic scene analysis of dog bite mark cases, paragraph 2, "at the crime scene with modifications $[5,13] . "$ 